\title{
Properties of the Aftershock Sequence of the $1999 M_{\mathrm{w}}$ 7.1 Hector Mine Earthquake: Implications for Aftershock Hazard
}

\author{
by Stefan Wiemer, Matt Gerstenberger, and Egill Hauksson
}

\begin{abstract}
We investigate the spatial and temporal seismicity parameters and the related probabilistic aftershock hazard for the aftershock sequence of the $1999 M_{\mathrm{w}}$ 7.1 Hector Mine mainshock and compare it with the neighboring $1992 M_{\mathrm{w}} 7.3$ Landers sequence. Using a catalog of 11,000 earthquakes, we determine the earthquake size distribution ( $b$-value), the aftershock decay rate ( $p$-value), and the seismic activity rate ( $a$-value). The $b$-values are high $(b>1.2)$ within the rupture area, significantly lower $(b \approx 0.7)$ north of the rupture area, and increase with time since the mainshock. Probabilistic aftershock hazard maps, computed automatically as early as 4 days after the mainshock, identified the northernmost part of the sequence as the highest-hazard region. These maps show a good agreement between the forecasts and the recorded large aftershocks. Based on the asymmetrical $b$-value and hazard patterns for both the Hector Mine and Landers sequences, we hypothesize that the mainshock rupture directivity and slip distribution influence aftershock hazard. Current static or dynamic stress triggering models cannot resolve this spatial and temporal evolution of the hazard. Stress tensor inversions of 1400 relocated first-motion focal mechanisms show predominantly a strike-slip stress state with a SW-NE trend of the greatest principal stress. The heterogeneity of the stress field is unusually high near the Hector Mine and Landers mainshock ruptures, particularly near patches of large slip.
\end{abstract}

\section{Introduction}

The aftershocks following a large to moderate mainshock are both a rich source of information and a potential hazard. The numerous aftershocks recorded following the $1999 M_{\mathrm{w}} 7.1$ Hector Mine and the $1992 M_{\mathrm{w}} 7.3$ Landers mainshocks offer the rare opportunity to compare two aftershock sequences that occurred under very similar conditions. The Hector Mine earthquake, a right-lateral strike-slip event, is described in detail in other articles in this issue (e.g., Hauksson et al., 2002). The objective of this study was to provide an in-depth analysis of the fine-scale structure of the Hector Mine aftershock sequence, to analyze the implications for aftershock hazard assessment, and to compare it with the Landers aftershock sequence.

In pioneering studies, Toda et al. (1998) and Wiemer and Katsumata (1999) systematically analyzed the spatial heterogeneity of seismicity within individual aftershock zones. These studies have demonstrated that the seismic activity, $a$, the size distribution of events, $b$, and the decay rate, $p$, all show significant spatial variations. Thus, assigning overall $a-, b-$, and $p$-values to entire aftershock sequences is an oversimplification of the complex and spatially heterogeneous internal structure of aftershock sequences. This spatial complexity may be caused by the physical parameters governing the decay rate and size distribution, such as stress, material properties, and pore pressure that are likely to vary substantially throughout an extensive aftershock volume. Hence, aftershocks near one section of a fault may be considered largely independent from the activity on another section (Wiemer and Katsumata, 1999).

Strong spatial variations of the earthquake size distribution expressed in terms of the $b$-value, on scales of 1-50 $\mathrm{km}$, have also been determined in different tectonic regimes, ranging from small scales, such as volcanic systems (Wiemer and McNutt, 1997; Wiemer et al., 1998), to regional scales (e.g., Ogata et al., 1991; Wyss et al., 2000, Gerstenberger et al., 2001a). Stress is also a factor involved in perturbing the $b$-value (Urbancic et al., 1992; Wyss, 1973; Lahaie and Grasso, 1999; Wiemer and Wyss, 2000). The Landers earthquake affected the regional seismicity at distances greater than $100 \mathrm{~km}$ and for periods exceeding 7 years (Wyss and Wiemer, 2000). It increased the overall $b$-value and modified seismicity rates, both increasing and in some volumes significantly decreasing the rates of small earthquakes. The physical mechanisms that cause these spatial and temporal changes in the aftershock seismicity are poorly understood. Because the probabilistic estimate of earthquake 
hazard depends on earthquake size distribution, an improved understanding of the controlling factors of the earthquake size distribution is needed. To move toward this objective, we also analyze the heterogeneity of focal mechanism within the aftershock seismicity.

Aftershocks may pose a significant hazard to populated areas. For example, an M 5.8 aftershock of the 1999 M 7.4 Izmit, Turkey, mainshock killed 7 and injured 420 people. In some regions of the world, measures have been implemented to assess this hazard in near real time to assist decision makers in determining when it is safe to demolish, repair or reoccupy damaged structures (Reasenberg and Jones, 1989, 1990, 1994; Reasenberg and Matthews, 1990; Hough and Jones, 1997). Starting with the 1989 M 7.2 Loma Prieta, California, earthquake, probabilistic forecasts of aftershock activity for large earthquakes in California were conveyed to emergency response workers and the public in terms of likelihood of occurrence above a certain magnitude for a given time window (Reasenberg and Jones, 1990). In forecasts of aftershock activity, seismicity parameters are averaged over the entire extent of an aftershock sequence without spatial information.

Recently introduced probabilistic aftershock hazard (PAH) maps are a novel approach to describe the hazard after a mainshock (Wiemer, 2000). They depict the spatially varying hazard in terms of physical parameters (e.g., the predicted peak or spectral ground motion) and are interpretable in the same manner as the maps used to portray mainshock hazard (e.g., Frankel, 1995; Giardini, 1999). When applied to the 1992 Landers sequence, the PAH maps correctly identified regions of increased likelihood of strong ground shaking. A systematic test of the capabilities and limitations of PAH maps is underway (Gerstenberger et al., 2001b). The occurrence of the Hector Mine mainshock offered an opportunity to test the feasibility of the real-time applicability of PAH maps. Based on the results from the a posteriori Landers analysis (Wiemer, 2000), PAH maps for the Hector Mine region were computed, starting four days after the mainshock. The maps were made available on the Internet to a number of seismologists and were updated daily. Here we report results from this first automated near-real-time application of PAH maps.

\section{Data and Method}

\section{Data Sets}

Hypocenters and local magnitudes for the aftershocks of the Landers and Hector Mine sequences were obtained from the Southern California Seismic Network (SCSN), operated jointly by the U.S. Geological Survey (USGS) and Caltech (Fig. 1). In addition to the regular SCSN catalog of hypocenters, we also use a relocated catalog of focal mechanisms that are based on first motion observations (Hauksson, 2000). These were determined for the relocated aftershocks that had more than 12 first motions available, and

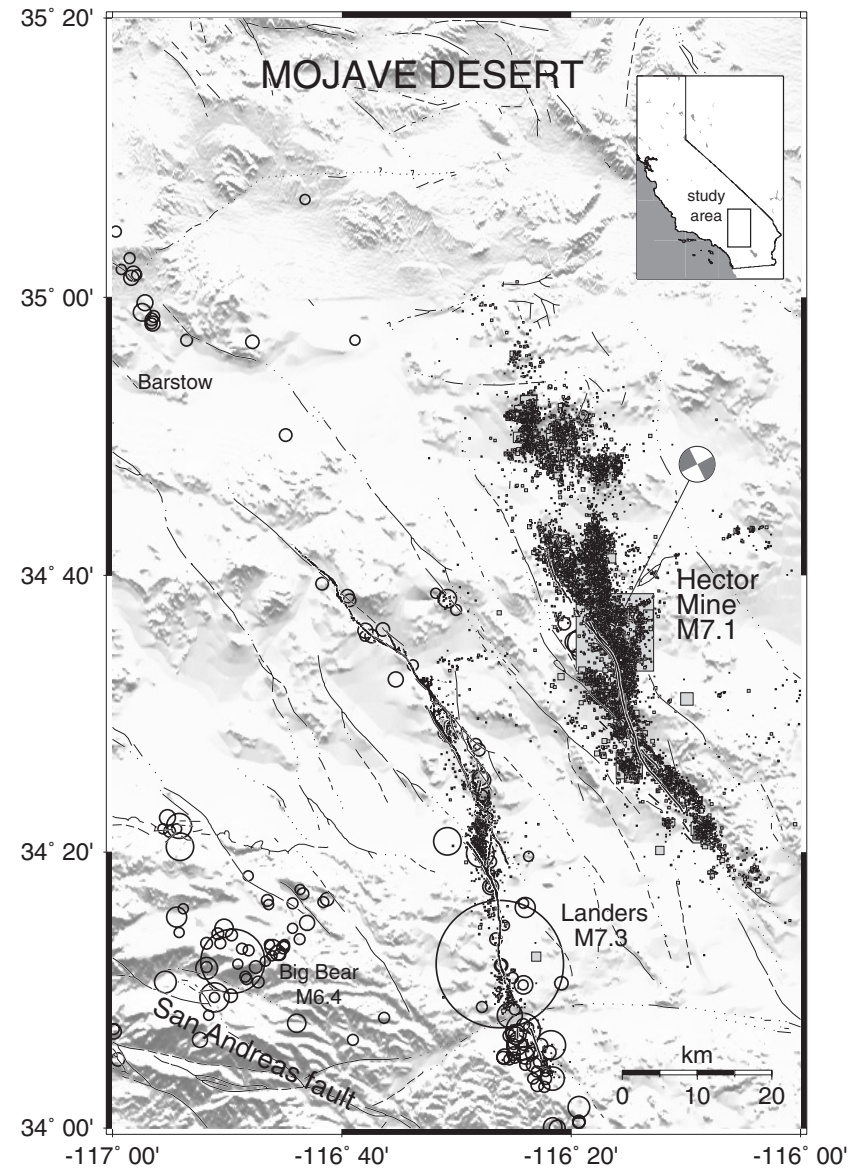

Figure 1. Map of the Mojave Desert region, showing aftershock sequences studied. Squares mark aftershocks to the $1999 M_{\mathrm{w}}$ 7.1 Hector Mine mainshock, symbol size is proportional to magnitude. Also plotted is the focal mechanism. Thin black lines mark mapped faults. The location of the 1992 M 7.3 Landers and, $M$ 6.4 Big Bear mainshocks are marked with large circles.

they used the approach of Reasenberg and Oppenheimer (1985). See Hauksson et al. (2002) for more details.

\section{Estimating the Magnitude of Complete Reporting}

The magnitude above which all events have been recorded, $M_{\mathrm{c}}$, is important for all seismicity-based studies (Wiemer and Wyss, 2000). Considerable spatial and temporal variations in $M_{\mathrm{c}}$ are common in seismicity catalogs and can be introduced by changes in the configuration of the seismic network or the processing approach. For our study, the $M_{\mathrm{c}}$ estimation is needed to determine seismicity parameters and hazard correctly. Assessing $M_{\mathrm{c}}$ is important for analyzing aftershock sequences, because completeness changes with time, in particular during the first days of the aftershock sequence (Wiemer and Katsumata, 1999). To obtain a first-order estimate of $M_{\mathrm{c}}$, we measure completeness by the goodness of fit of the frequency-magnitude distribution to a power law (Wiemer and Wyss, 2000). Complete- 
ness is assumed when a power law can explain $95 \%$ of the variance of the frequency-magnitude distribution. If the completeness is varying strong with time, the $M_{\mathrm{c}}$ estimate is less reliable.

We determine $M_{\mathrm{c}}$ as a function of time for the Hector Mine sequence using a moving window approach: $M_{\mathrm{c}}$ is estimated for samples of 100 events, starting at the mainshock time. The window is then moved by 50 events. $M_{\mathrm{c}}$ decreases, roughly exponentially, from $M_{\mathrm{c}}$ about 3.5 in the first hours to $M_{\mathrm{c}}$ about 2.2 after 3 days (Fig. 2A). A subsequent increase in $M_{\mathrm{c}}$ after 4.5 days is correlated with the occurrence of an $M 5.1$ and an $M 5.0$ aftershock, marked by stars in Figure 2A. $M_{\mathrm{c}}$, however, remains consistently below 2.0 once the first 2 months of the sequence have passed (Fig. 2B). We also estimate $M_{\mathrm{c}}$ as a function of space, applying the mapping technique by Wiemer and Wyss (2000). Maps of $M_{\mathrm{c}}$, based on the first 0.1 to 3 days (Fig. 3A) and the period 3 to 600 days (Fig. 3B), are computed for the Landers and Hector Mine sequences and plotted both on one map. Maps are computed using volumes of constant radii $(5 \mathrm{~km})$ and a grid spacing of $2 \mathrm{~km}$. For the first 3 days of the Landers sequence, $M_{\mathrm{c}}$ is approximately 2.8 in the northernmost part of the aftershock volume (dark colors). During the Hector Mine sequence, $M_{\mathrm{c}}$ is approximately 2.4 in the first 3 days. The lower level of aftershock activity during the first days of the Hector Mine aftershock sequence and the improved monitoring system made it possible to record to smaller magnitudes than was possible during the Landers sequence. The $M_{\mathrm{c}}$ values on the map are lower than the maximum values obtained in the temporal analysis (Fig. 2) because (1) we eliminated the first 0.1 days from the analysis and (2) the $M_{\mathrm{c}}$ estimation for the subsets at each node does not have the temporal resolution to resolve the higher $M_{\mathrm{c}}$ in the first hours. The difference in completeness between the northern and southern part of both aftershock sequences remains visible throughout the later part of each sequence (Fig. 3B). The difference is much more pronounced for the Landers sequence because the southern tip of the Landers aftershock sequence is monitored down to a very small magnitude of about 1.3. This difference is probably caused by the configuration of the SCSN network, with fewer stations north of the hypocenters. To confirm the temporal changes in $M_{\mathrm{c}}$, we show two frequency-magnitude distributions (FMD), comparing the 250 events nearest the Hector Mine hypocenter for the two respective periods of investigation (0.1-3 days and 3-600 days) (Fig. 4A). A clear decrease in completeness by about 0.5 magnitude units is visible, whereas the $b$-value remains approximately constant. During the later period black triangles in (Fig. 4A), there is a noticeable change in curvature of the FMD below $M_{\mathrm{c}}$, suggesting that completeness gradually improved later in the sequence. Although spatial variations in $M_{\mathrm{c}}$ of up to 0.5 magnitude units exist, the temporal variations in the first few days after the mainshock of up to 1.2 magnitude units are more relevant for aftershock seismicity analysis (Figs. 2-4).
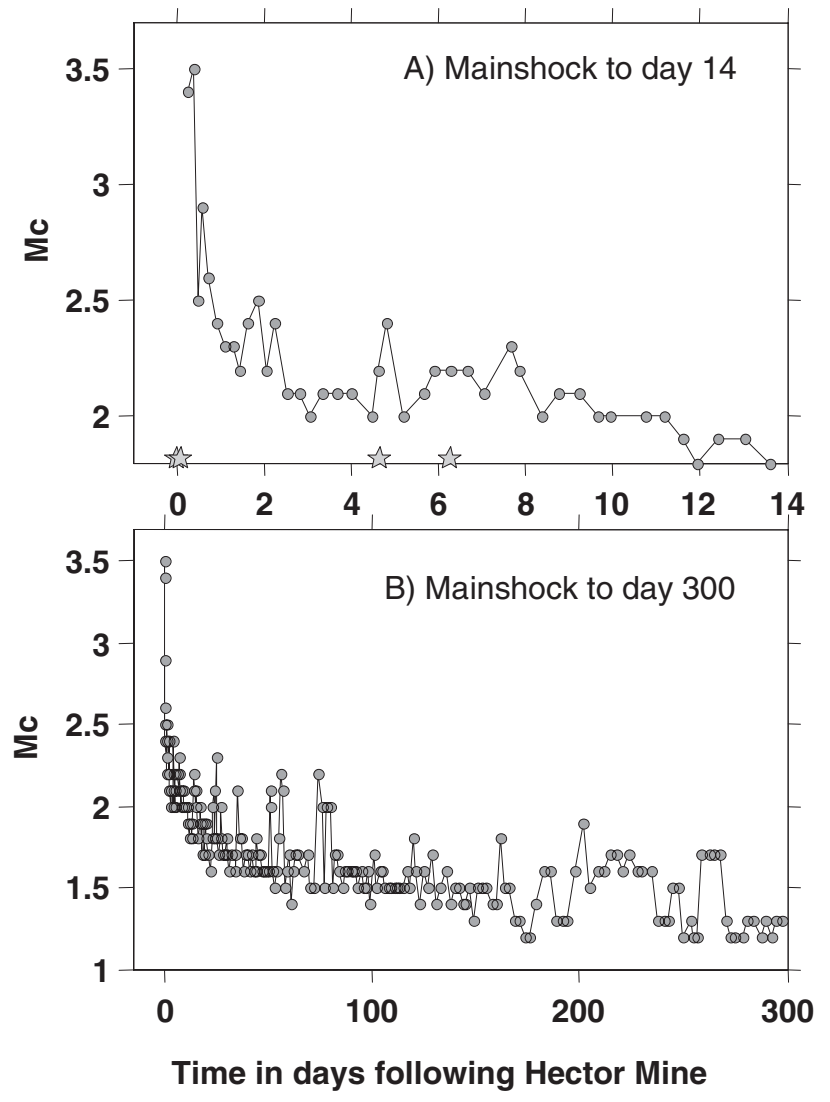

Figure 2. Plots of $M_{\mathrm{c}}$, the magnitude of completeness, with time for the Hector Mine aftershock sequence. Values were calculated using a window of 100 events, with $M_{\mathrm{c}}$ calculated every 50 events. The mainshock occurred at time 0. (A) First 14 days of the sequence. Stars plotted along the base represent all aftershocks $M \geq 5$.0. (B) First 300 days of the aftershock sequence.

\section{Estimating the Frequency-Magnitude Distribution}

The size distribution of earthquakes is in most cases well described by the Gutenberg-Richter relationship (Ishimoto and Iida, 1939; Gutenberg and Richter, 1944): $\log _{10} N$ $=a-b M$, where $N$ is the cumulative number of earthquakes with magnitudes of $M$ or larger, $b$ describes the size distribution of events (a smaller $b$ indicates a higher proportion of larger events), and $a$ is proportional to the productivity of a volume, or the seismicity rate. We map $a^{\prime}=$ ( $a$ at $M_{\mathrm{c}}$ ), the number of events $\geq M_{\mathrm{c}}$, because this representation decouples the productivity from the $b$-value, which is needed to extrapolate to $a$ at magnitude zero. Various methods have been suggested to measure $b$ and its confidence limits (Aki, 1965; Utsu, 1965, 1992; Shi and Bolt, 1982; Bender, 1983; Frohlich and Davis, 1993; Kagan, 1999). In our study, the $b$-value is calculated by the maximum likelihood method (Aki, 1965) and the uncertainty in $b, \Delta b$, following Shi and Bolt (1982). We estimate the probability that two samples come from the same population by Utsu's (1992) test. 


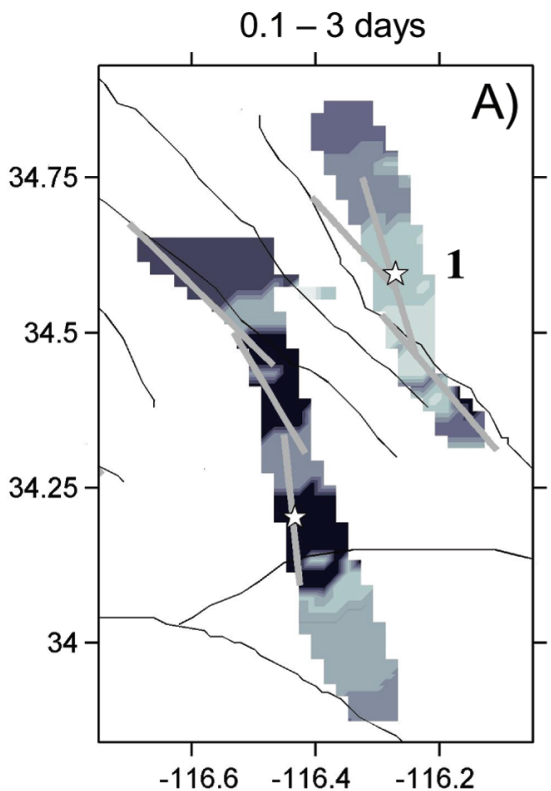

Mc

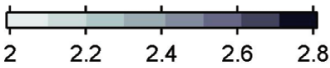

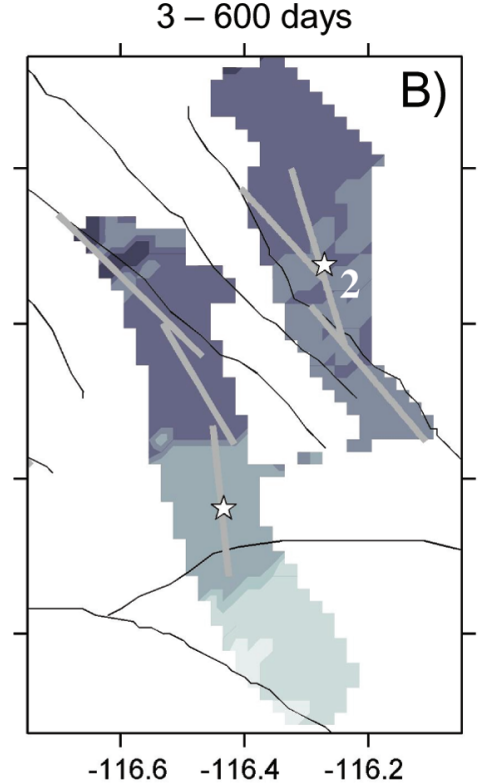

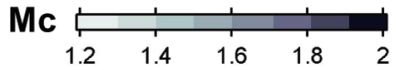

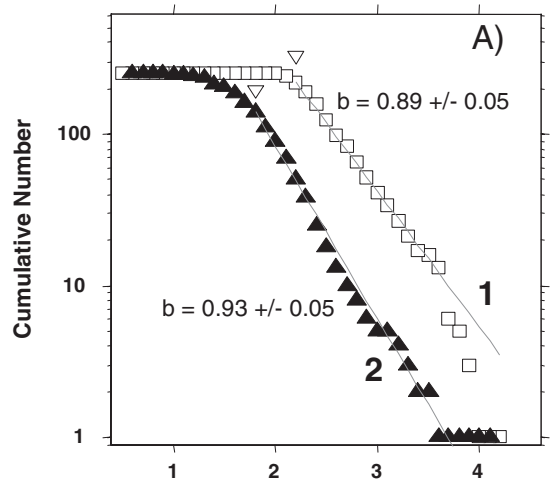
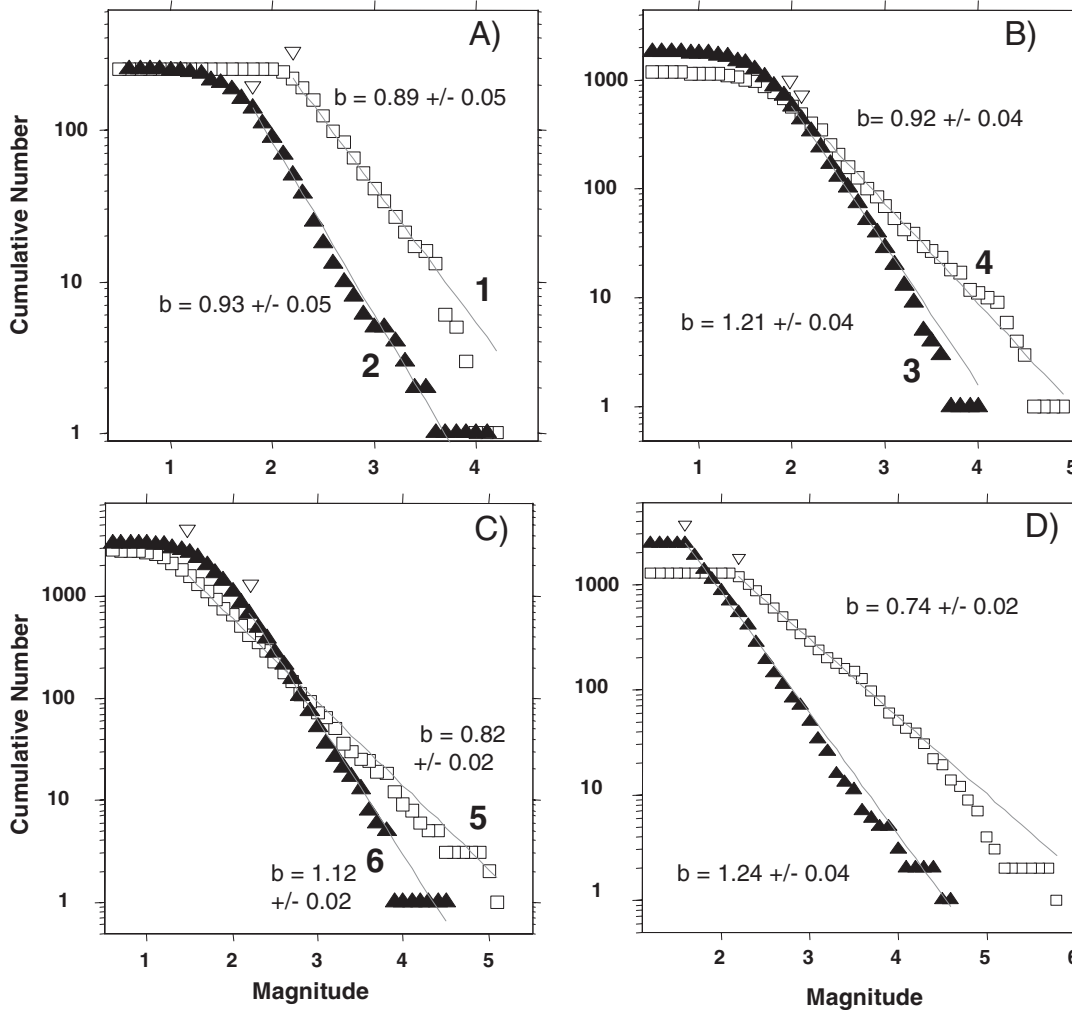

Figure 3. Surface maps of the spatial distribution of $M_{\mathrm{c}}$ for the Landers and the Hector Mine aftershock sequences. (A) The period 0.1-3 days after the mainshock for each aftershock sequence. (B) The time period 3-600 days for each aftershock sequence. Note the different scaling for each frame. Gray lines mark the fault segments that ruptured in the mainshocks, stars mark hypocenter locations. Maps were obtained by sampling events within a $5-\mathrm{km}$ radius from each node. Frequencymagnitude distributions obtained from the Hector Mine hypocenter for the two periods are compared in Figure 4A (marked 1 and 2).
Figure 4. Frequency-magnitude distributions (FMD) for selected volumes. (A) Hector Mine hypocenter, nearest 250 earthquakes. Squares: Period 0.1-3 days. Triangles: 3-600 days. (B) Triangles: Northern part of the Landers sequence, period 3-600 days, $R=8 \mathrm{~km}$ (marked 3 in Fig. 5B). Squares: South of the Landers hypocenter, period 3-600 days, $R=$ $8 \mathrm{~km}$ (marked 4 in Fig. 5B). (C) Squares: North of the Hector Mine hypocenter, period 3-600 days, $R=8 \mathrm{~km}$ (marked 5 in Fig. 5B). Triangles: North of Hector Mine rupture, period 3-600 days, $R=8 \mathrm{~km}$ (marked 6 in Fig. 5B). (D) Comparison of the FMD for the first 7 days (squares) of the entire Hector Mine aftershock sequence and the period 1 January 2000-30 June 2000 (triangles). 


\section{Estimating the Aftershock Decay Rate}

The decay of activity with time is described by the modified Omori law (Kisslinger and Jones, 1991; Utsu et al., 1995):

$$
R(t)=\frac{k}{(t+c)^{p}}
$$

where $R(t)$ is the rate of occurrence of aftershocks and $k, c$, and $p$ are constants. Of these three parameters, $p$ is the most important. It measures the exponential decay rate of aftershocks. A larger $p$ represents a faster decay. Between different aftershock sequences, the average value of $p$ was found to vary within California between 0.7 and 1.8 (Kisslinger and Jones, 1991), whereas Wiemer and Katsumata (1999) showed that the $p$-value also varies spatially within individual aftershock sequences between about 0.6 and 1.4.

\section{Probabilistic Aftershock Hazard Assessment}

Probabilistic aftershock hazard assessment is based on the two power laws that describe the size distribution of earthquakes and the temporal behavior of an aftershock sequence. From the modified Omori and Gutenberg-Richter laws, one can obtain an equation (Reasenberg and Jones, $1989,1990,1994)$ that describes the rate $\lambda(t, M)$ of aftershocks of magnitude $M$ or larger:

$$
\lambda(t, M)=10^{a+b\left(M_{\mathrm{m}}-M\right)}(t+c)^{-p}
$$

where $t$ is the time after the mainshock and $M_{\mathrm{m}}$ is the mainshock magnitude. By modeling the aftershock sequences as a Poisson process with a time-dependent rate parameter (Reasenberg, 1985), we derive the probability $P$ of one or more earthquakes occurring in the magnitude range $\left(M_{1} \leq\right.$ $\left.M<M_{2}\right)$ and time range $(S \leq t<T)$ :

$$
P=1-\exp \left(-\int_{T}^{S} \lambda(t, M) d t\right)_{M_{1}}^{M_{2}}
$$

\section{Spatially Mapping Seismicity Parameters}

For spatial mapping of aftershock hazard, we use the gridding technique employed in previous studies of $b$-values and seismic quiescence (Wiemer and Wyss, 1994, 1997; Wiemer and Katsumata, 1999; Wiemer, 2001). Two-dimensional grids with several thousand nodes spaced regularly at 1 or $2 \mathrm{~km}$ are interactively selected for the study region, excluding areas of low seismicity. Next, the time and size distribution for either the $N$ nearest events to each node, or all events within a radius of $R$, are found, and $M_{\mathrm{c}}$ is estimated (Wiemer and Wyss, 2000; Wyss and Wiemer, 2000). The seismicity parameters ( $a$-, $b$-, and $p$-values) are then estimated at each node. We analyze nodes only where at least 50 events above $M_{\mathrm{c}}$ are available, although most nodes will have many more events. To map temporal changes of $b$ values we compute differential $b$-value maps in the following fashion (Wiemer et al., 1998): (1) calculate a $b$-value grid for the period $T_{1}$ to $T_{2}$, as described previously, using constant radii (e.g., $10 \mathrm{~km}$ ) per volume. (2) Calculate a $b$ value grid for the period $T_{3}$ to $T_{4}$, using the nodes defined in step 1. (3) Plot the difference in $b$, using a color code, if it is statistically significant at the $95 \%$ confidence level as measured by Utsu's (1992) test. Thus, these differential $b$ value maps identify volumes of significantly increased or decreased $b$-value.

\section{Translating Probabilities Into Peak Ground}

Accelerations: Probabilistic Aftershock Hazard Maps

The probabilistic forecasts at each node are translated into hazard maps depicting a probabilistic forecast of the peak ground acceleration that will be exceeded for a given forecast period and probability level (Wiemer, 2000). Similar maps are familiar products of probabilistic hazard mapping studies (Frankel, 1995) and are used routinely to establish building codes for engineered structures in earthquake-prone areas. In general, however, hazard maps are calculated for low probabilities of exceedance (e.g., 10\%) and for long periods (e.g., 50 or 475 years). For aftershock hazard, much shorter periods of days to months and higher probabilities (e.g., 90\%) are of interest. Further, an aftershock hazard map is time dependent, whereas mainshock hazard maps are usually time independent and are generally based on the assumption of a stationary Poissonian distribution of seismicity. This assumption is clearly violated in aftershock zones. Therefore, conventional hazard maps cannot portray aftershock hazard. In PAH maps, time dependence is integrated through the modified Omori law. Note that forecasts $P(t, M)$ for a given period are an average over the forecast period, with the probability and resulting hazard decreasing with time.

The computation of hazard maps requires information on attenuation (i.e., the decay of ground-motion amplitude with distance) and maximum magnitude, $M_{\max }$. For our study, we use the hazard mapping software SeisRisk III (Bender and Perkins, 1987) and the attenuation relationship for an average hard-rock site (NEHRP class C soil) for the Western United States (Boore et al., 1994). To simplify the approach, no information on site amplification is used. We set the largest aftershock to be 0.5 units smaller than the mainshock $\left(M_{\max }=M_{\text {main }}-0.5\right)$. In principle, aftershocks as large as or larger than the mainshock can also be considered (Reasenberg and Jones, 1989, 1990).

The computation of PAH maps using SeisRisk III requires the definition of source zones. We use rectangular zones, which are defined mostly automatically, based on the number of events and their spatial distribution as follows. (1) Based on the first few hours of aftershocks, the SW (34.35 N/116.00W) and NE (34.9N/116.5W) corners of the extent of the aftershock zone are defined. (2) We require 
each source zone arbitrarily to have at least 100 events. To define the number of source zones, we first estimate overall completeness and remove aftershocks of magnitude lower than $M_{\mathrm{c}}$, and sort the remaining aftershocks according to latitude. We then obtain $N_{\mathrm{s}}$, the number of source zones, by dividing the number of earthquakes in the complete dataset by 100 and rounding down to the closest integer (e.g., 480 earthquakes-4 source zones with each 120 events). Horizontal source zone boundaries are then created at the latitude of the $n \times N_{\text {total }} / N_{\mathrm{s}}$ event, $\left(n=1,2,3 \ldots N_{\mathrm{s}}\right)$. (3) To limit the vertical extent of the source zones, we estimate the longitude of the 25th and 75th percentiles of the longitudes of the subset. (4) Seismicity parameters $(a, b, p)$ are estimated from all events within a subset and used to compute $\lambda(t, M)$ and $P$. Automatically repeating steps $2-4$ as new data become available results in a successively more detailed hazard map.

\section{Stress Tensor Inversions}

Stress tensor inversions resolve the orientation of the three principal stresses $\left(S_{1}, S_{2}\right.$, and $\left.S_{3}\right)$ of the stress ellipsoid, their relative magnitude, and the homogeneity of the stress field, given a sufficiently heterogeneous set of focal mechanisms. Several inversion algorithms have been proposed in the past (e.g., Gephart and Forsyth, 1984; Michael, 1984, 1991; Gephart, 1990a; Michael et al., 1990) and have been shown to compute consistent results (Hardebeck and Hauksson, 2001). We choose the faster method of Michael (1984, 1987) to investigate local variations of the state of stress within the Landers and Hector Mine aftershocks. We use the relocated and quality-controlled data set of focal mechanisms provided by Hauksson (2000). Our analysis is limited to the best-determined focal mechanisms (solution misfit $<0.15$ ), with a total of 2200 mechanisms for the Landers and 1160 mechanisms for the Hector Mine sequence. Because the fault and auxiliary plane cannot be distinguished, they are assumed to be equally likely in the inversion. We invert for the stress tensor at each node using a grid spacing of $2 \times 2 \mathrm{~km}$ and utilizing all mechanisms within $8 \mathrm{~km}$ at all depths. For each sample, we require at least 15 available mechanisms to compute an inversion. To verify that the sampling method has no influence on the inversion results, we also compute maps for varying radii and constant number of events and found no significant difference in the results. We classify the various tectonic regimes (normal, strike slip, thrust faulting) following Zoback (1992). In the framework of this study, we are more interested in the homogeneity of the stress field than the orientation of $S_{1}, S_{2}$, and $S_{3}$. To map the homogeneity of the stress field we use the variance of the resulting stress tensor, defined as the solution misfit (the angle between the individual focal mechanism and the assumed stress tensor) squared and summed (Michael 1987, 1991). A low variance $(<0.1)$ indicates that one stress tensor can explain the observed focal mechanism, and, therefore, stress in this particular volume can be assumed homogeneous. High variance $(>0.2)$ on the other hand indicate a poor fit to one stress tensor, suggesting that the stress field remains spatially or temporally heterogeneous within the analyzed volume (Lu et al., 1997).

The software package used to spatially and temporally map seismicity, ZMAP, and data sets used in this study are freely available via anonymous ftp (http://www.seismo.ethz. ch/staff/stefan; Wiemer, 2001).

\section{Results}

Mapping the Earthquake Size Distribution and Aftershock Decay Rate

The overall seismicity parameters extracted for each sequence and for the two periods of 0-3 days and 3-600 days are given in Table 1. Maps of the spatial distribution of the $a-, b-$, and $p$-values were computed using the aftershocks for the period 3-600 days after the mainshocks for each sequence (Fig. 5), applying an overall $M_{\mathrm{c}}$ cut of 2.4 for the Landers-Big Bear sequence and 2.1 for the Hector Mine sequence. These parameter sets are extracted from the analysis of temporal and spatial completeness (Fig. 2-4). The selection is somewhat arbitrary, because time after the mainshock trades off with completeness; however, we verified that different parameter sets within the suitable range extracted from the $M_{\mathrm{c}}$ analysis give similar results. We sample the aftershocks within $5 \mathrm{~km}$ of each node, using a grid spacing of $1 \mathrm{~km}$, and compute the $a-, b$-, and $p$-values (Fig. 5). The productivity, $a^{\prime}$, or number of events $\geq M_{\mathrm{c}}$ ranges from the allowed minimum of 50 events per volume to about 400 (Fig. 5A). The highest density of aftershocks within the Hector Mine sequence is observed north of the hypocenter (blue areas in Fig. 5A). The productivity within the Landers sequence exceeded the Hector Mine sequence considerably (Table 1), particularly when one considers the higher $M_{\mathrm{c}}$ cut. When filtering both sequences at the same completeness level of $M_{\mathrm{c}} 2.4$, and summing the events in the period 3600 days, we find 1927 events in the Hector sequence and 3603 in the Landers sequence. Therefore, the productivity of Landers was almost twice that of than Hector Mine. Within the Landers sequence, the two regions of highest activity are revealed (purple in Fig. 5A), about midway and at the northern end of the mainshock rupture.

\section{Table 1}

Overall Seismicity Parameters for the Three Aftershock Sequences

\begin{tabular}{lccrcc}
\hline Earthquake & Period (days) & $M_{\mathrm{c}}$ & $N>M_{\mathrm{c}}$ & $b$-Value & $p$-Value \\
\hline Landers & $0-3$ & 2.8 & 463 & $0.84 \pm 0.04$ & $\mathrm{NA}$ \\
& $3-600$ & 2.4 & 2100 & $1.20 \pm 0.05$ & $1.17 \pm 0.03$ \\
Big Bear & $0-3$ & 2.6 & 250 & $0.67 \pm 0.04$ & $\mathrm{NA}$ \\
& $3-600$ & 2.4 & 895 & $1.03 \pm 0.04$ & $1.03 \pm 0.04$ \\
Hector Mine & $0-3$ & 2.4 & 597 & $0.72 \pm 0.03$ & $1.09 \pm 0.18$ \\
& $3-600$ & 2.1 & 3124 & $1.18 \pm 0.02$ & $1.14 \pm 0.03$ \\
\hline
\end{tabular}



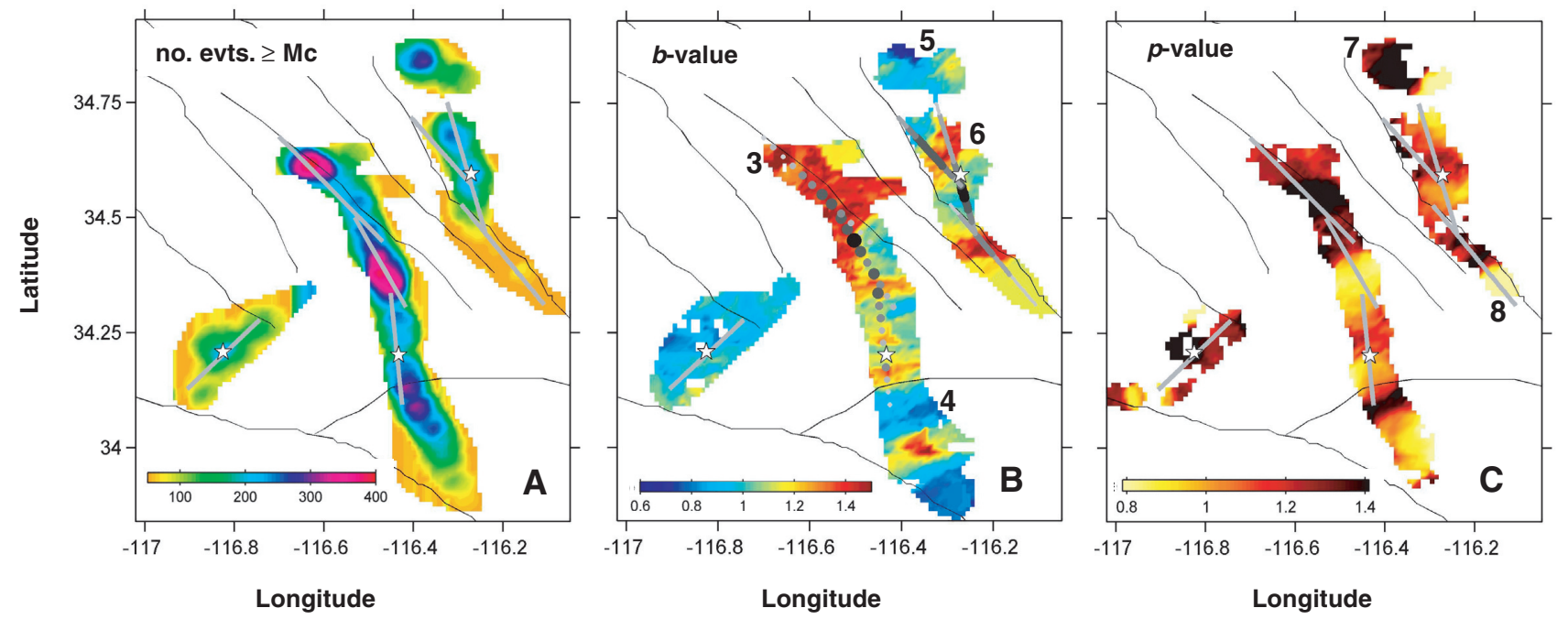

Figure 5. Map of the Landers-Hector Mine region, showing (A) number of earthquakes above $M_{\mathrm{c}}$, (B) $b$-value, and (C) $p$-value. Each map is based on the period 3 600 days after the 1992 Landers-Big Bear and 1999 Hector Mine mainshocks. Stars indicate the mainshock epicenters. The gray lines represent the surface fault rupture; thin black lines are mapped faults in the region. In frame B, the mean slip distribution during the mainshocks is keyed to symbol size and grayscale (more slip: darker and larger symbol). Locations of the volumes for which the frequency magnitude distributions are shown in Fig. 4B,C are marked 3-6. Locations of the volumes for which the activity as a function of time are plotted in Fig. 6 are marked 7 and 8.

The spatial distribution of the $b$-value varies by factor of 2.5 between the different parts of the aftershock sequences (Fig. 5B). The highest $b$-values (red in Fig. 5B) are found in the northernmost portion of the Landers sequence. Within the central and southern portion of the Hector Mine aftershock sequence, $b$-values are also high $(1.2<b<1.6)$. The lowest $b$-values are found for both sequences outside the actual rupture area (marked as gray lines). Four individual frequency-magnitude distributions (FMDs) for selected volumes of radius $5 \mathrm{~km}$ (marked 3-6 in Fig. 5B) are shown in Figure 4B and C. Using Utsu's (1992) test, differences in $b$ value can be established as highly significant $(>99.9 \%)$. For comparison, we show at top of Fig. 5B is the mean slip distribution obtained for the two mainshocks (Wald and Heaton, 1994; Ji et al., 2000).

The spatial variations in $p$ range from 0.8 to 1.6 (Fig. 5C). The highest $p$-values (dark colors), which indicate a fast decay of aftershock activity, are found north of the Hector Mine rupture area and in the northernmost part of the Landers rupture, as well as in the Big Bear area. Several areas of low $p$-value, indicating slow decay of the aftershock activity, can be found within each aftershock sequence. In Figure 6, we compare two volumes of different $p$-value from within the Hector Mine sequence. The seismicity in the northernmost part decays much faster $(p=1.76)$ than along the southern part of the sequence $(p=1.0)$. The high $p$ value region cannot be fit well with a simple modified Omori law for approximately the first 10 days, because larger aftershocks occured during this period.

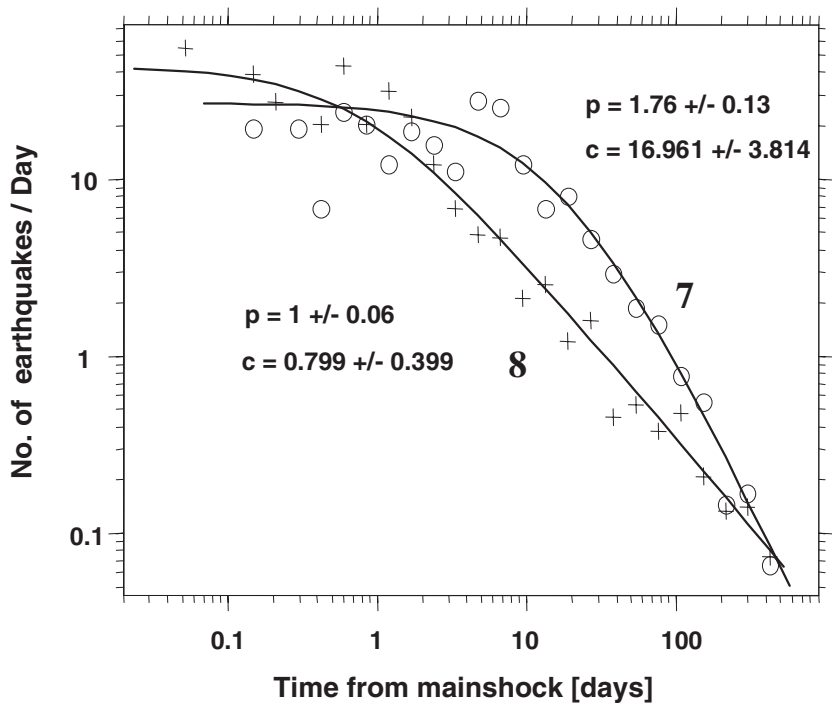

Figure 6. Comparison of the temporal decay of the aftershock activity between two volumes within the Hector Mine aftershock sequence. Circles: Northern part of the Hector Mine aftershock volume (marked 7 in Fig. 5C). Crosses: Southern part of the Hector Mine aftershock volume (marked 8 in Fig. $5 \mathrm{C})$. 
A

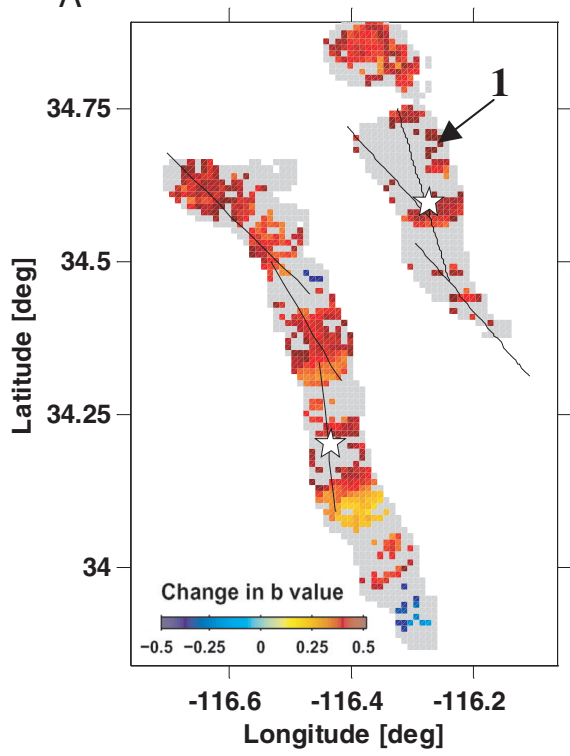

B

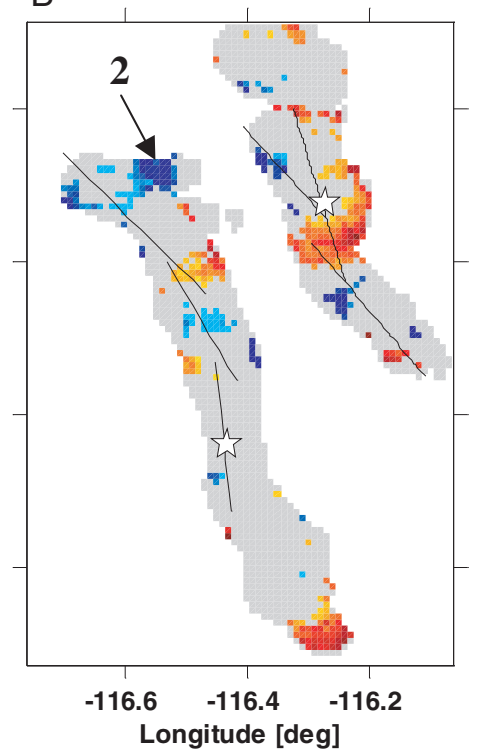

Figure 7. Maps of the Landers-Hector Mine region showing the differential change in $b$-value between different time periods. Only differences that were determined to be significant at the 95\% level, based on Utsu's (1992) test, are colored. Areas in gray either lacked sufficient data to obtain a result, or did not contain a significant change. (A) The first 7 days of each sequence as compared to day 7 to day $30\left(b_{7-30}-b_{0-7}\right)$. The dominant trend is an increase in $b$-value. (B) Day 7 to day 30 as compared to day 30 to day $300\left(b_{30-300}-b_{7-30}\right)$. Locations for the Frequency-magnitude distributions shown in Figure 8 are marked (1 and 2).
Temporal Changes of the $b$-Value

We determine the change in $b$-value with space and time using differential $b$-value maps. The aftershock region is sampled using volumes with constant radii of $5 \mathrm{~km}$. We show comparisons for two periods: $7-30$ days minus $0-7$ days (Fig. 7A) and 30-300 days minus 7-30 days (Fig. 7B). Only nodes where a difference in $b$-value can be established at the 95\% confidence level are colored. After the first 7 days, the $b$-value increased for a majority of the nodes (Fig. 7A, red colors). The comparison between 7-30 days and 30300 days, on the other hand, shows significant change in $b$ value only in about $20 \%$ of the nodes, with increases and decreases approximately equally common. A comparison of the FMDs for the different periods in two volumes (marked 1 and 2 in Fig. 7A and 7B, respectively) are shown in Figure 8. The difference in $b$-value is significant $(>99.9 \%)$ in the first volume, but only marginally significant in the second. We also analyze the change of the $b$-value as a function of time for the entire Hector Mine sequence (Fig. 9). A systematic increase of $b$ can be observed, with $b<1.1$ in the first weeks and $b \approx 1.2$ afterward. A comparison of the FMD for the first 7 days $\left(M_{\mathrm{c}}=2.2 ; b=0.73 \pm 0.03\right)$ of the aftershock sequence and the period 1 January 2000-30 June 2000 $\left(M_{\mathrm{c}}=1.7 ; b=1.24 \pm 0.04\right)$ is shown in Figure 4D. The increase in $b$-value for the later part of the Hector Mine sequence is highly significant and is not caused by completeness problems.

\section{Aftershock Hazard Mapping}

PAH maps can be plotted using a multitude of parameter sets, and several free parameters can be selected when com-

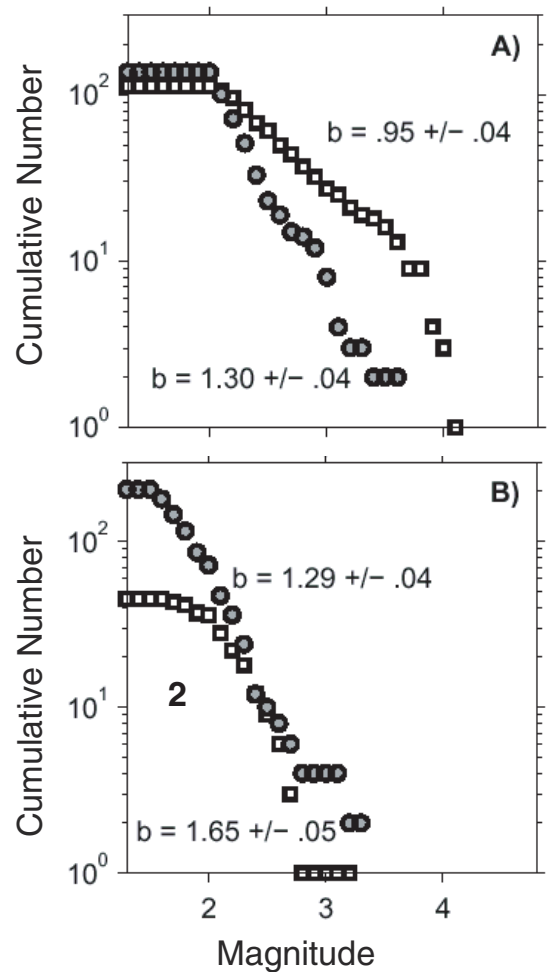

Figure 8. Selected Frequency-magnitude distributions (FMD) extracted from the differential $b$-value map (1 and 2 in Fig. 7). The squares represent the initial time period in each sequence. The location of each region is plotted in Fig. 6. (A) FMD comparing the first 7 days to day 7 to 30 in the Hector Mine sequence. (B) FMD comparing day 7 to 30 to day 30 to 300 for the Landers sequence. 


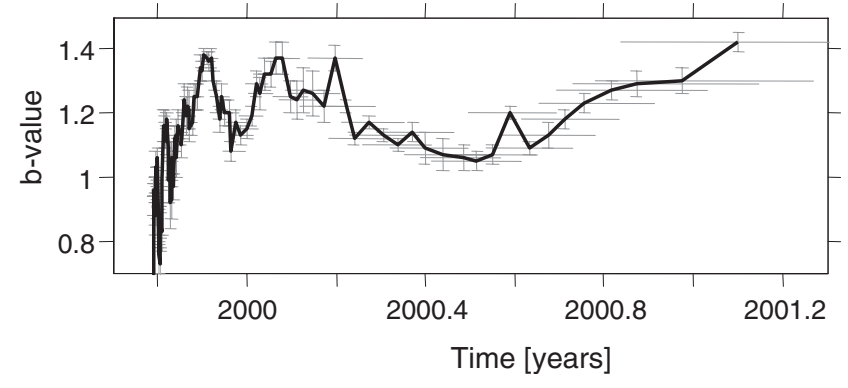

Figure 9. The $b$-value as a function of time for the Hector Mine sequence. The $b$-value was computed for overlapping samples of 250 earthquakes each, taking into account the temporal variation of $M_{\mathrm{c}}$ (Fig. 2). Thin vertical lines mark the uncertainty in the $b$ value; horizontal bars, the period this estimate is based upon.

puting them: (1) the observation time period, (2) the forecast period, (3) the probability level, and (4) the number of source zones. The probability level has a large impact on the absolute value of the forecasted peak ground accelerations. The preferred selection depends on the interests of the user. For some users, it may be most important to get an accurate forecast of the sequence; hence a high probability of exceedance (e.g., 90\%) will be appropriate. Other users may be more interested in the worst-case scenario; hence a low probability of exceedance (e.g., 10\%) might be of interest. In this study, we arbitrarily choose the $33 \%$ probability level. To a large extent, the probability level only scales the predicted horizontal peak ground acceleration (HPGA) and does not change the distribution of the hazard. In the context of this study, we are interested only in showing a spatial correlation of the hazard forecast with subsequent larger aftershocks, not in the absolute level of the acceleration.

We compared the 30-day forecasts for 4, 14, 30, and 60 days after the mainshock for the same probability of exceedance $(33 \%)$ to determine how the aftershock hazard decreases with time (Fig. 10). We found that approximately 4 days is the minimum time required to compute a meaningful, spatially varying PAH map. The forecast hazard decreases from about $0.22 \mathrm{~g}$ to less than $0.03 \mathrm{~g}$ after 60 days. Large aftershocks that occur within each respective forecast period are marked as white dots $(4.0 \geq M>5)$ and triangles $(M$ $\geq 5.0$ ). In the period 4-34 days (Fig. 10A), $16 M 4+$ and 3 M 5 + earthquakes occurred; in the second forecast period, three $M 4+$ occurred (Fig. 10B). These events are located mostly to the north of the mainshock hypocenter, slightly north of the termination of its rupture. Thus, the areas of high predicted HPGA and the locations of the larger aftershocks show good agreement.

\section{Stress Tensor Inversion Results}

The stress tensor inversion results, based on samples with radii of $8 \mathrm{~km}$ and at least 15 focal mechanisms, for both the Landers and the Hector Mine sequences are shown in map view in Figure 11A. We analyzed the focal mechanisms from the first 450 days of aftershock activity (i.e., using data from the periods of 28 June 1992-31 Sept. 1993 and 16 Oct. 1999-31 Dec. 2000) (Figure 11A). The orientation of $S_{1}$ is indicated by a bar. Strike-slip faulting with a southwestnortheast trend is predominant ( $>90 \%$ of all mechanisms). The variance, $\sigma$, of the resulting stress tensor at each node is color coded. The highest values of $\sigma(\sim 0.3)$ are found near the Camp Rock/Emerson fault in the northernmost part of the Landers rupture and near the Hector Mine hypocenter. No increased variance is found near the Big Bear rupture. Plotted on Figure 11A is the mean slip distribution obtained for the two mainshocks (Wald and Heaton, 1994; Ji et al., 2000). We plot in Figure 11A as insets for two selected nodes of high and low variance, respectively, the orientation of the principal stress axes and their 95\% uncertainty limits (Michael, 1987). High variance regions show much broader confidence regions of the principal stress axes than the low variance regions, and the resolved principal stress directions and faulting regimes are unreliable.

To evaluate if the spatial distribution of $\sigma$ is stationary with time, we show in Figure $11 \mathrm{~B}$ and $\mathrm{C}$ inversion results based on the same grid and radii, but dividing the previous data into two periods (Fig. 11B: 28 June 1992-28 July 1992 and 16 October 1999-16 November 1999; Fig. 11C: 28 July 1992-30 September 1993 and 16 November 1999-31 December 2000). The resulting maps of $\sigma$ show the same general pattern. One noteworthy difference is that a slight decrease of $\sigma$ can be observed north of the Hector Mine hypocenter.

\section{Discussion}

Properties of the Hector Mine aftershock sequence vary systematically with location, and this influences the aftershock hazard profoundly. Our in-depth study of the finescale structure of the Hector Mine aftershocks sequence reveals that the earthquake-size distribution (Fig. 5B), the aftershock decay rate (Fig. 5C), the aftershock rate (Fig. 5A), and the homogeneity of the stress field (Fig. 11) vary spatially and temporally. Consequently, the calculated aftershock hazard varies between the two ends of the Hector Mine mainshock rupture (Fig. 10).

The earthquake size distribution varies spatially by up to a factor of 2.5 (Fig. 5B). High $b$-values $(b>1.2)$ are found near the rupture areas, and low to normal $b$-values $(b$ $<0.9$ ) are found south of the Landers rupture and north of the Hector Mine rupture. The Landers and Hector Mine aftershock sequences are quite similar in the absolute values of $b$-value. The spatial differences in $b$-value within each sequence are highly significant (Fig. 4B, C) and are consistent with the findings of and are consistent with the findings of Wiemer and Katsumata (1999) that indicated strong spatial variability in $b$-value for the 1994 Northridge, 1995 Kobe, 1984 Morgan Hill, and 1992 Landers earthquakes. The temporal and spatial variability of $M_{\mathrm{c}}$ (Fig. 2-4) can at 

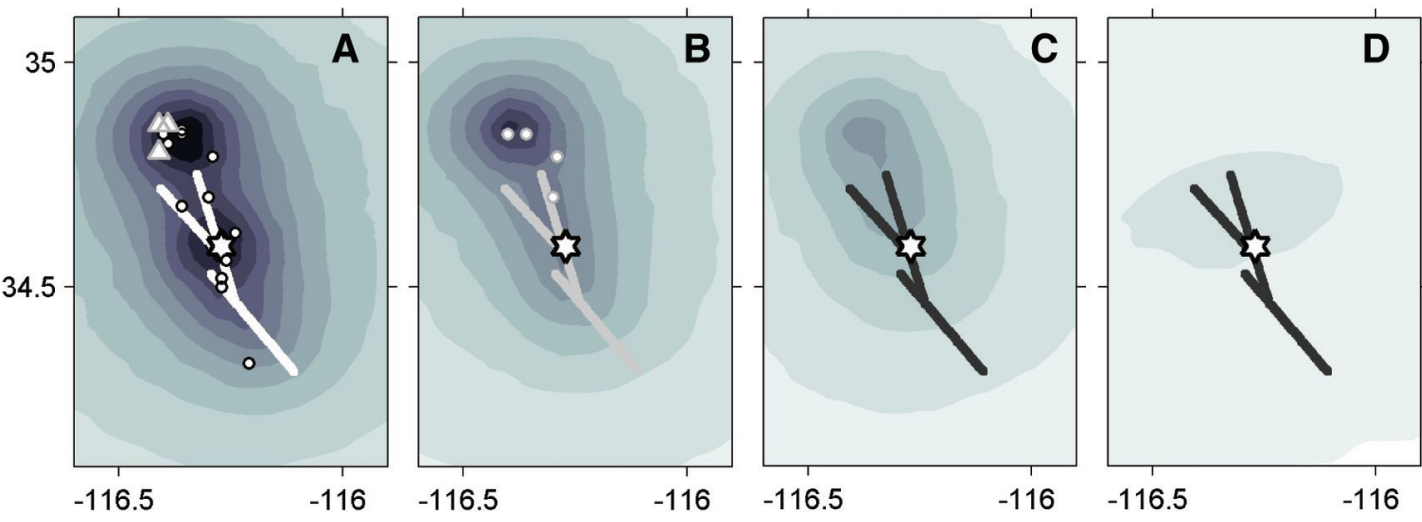

Figure 10. Probabilistic aftershock hazard maps for the same probability of exceedance $(33 \%)$ at varying times after the mainshock. Gray shading indicates the forecasted horizontal peak ground acceleration, computed (A) 4 days, (B) 14 days, (C) 30 days, and (D) 60 days after the mainshock, each forecasting the next 30 days. Gray lines mark the faults that ruptured in the Hector Mine mainshock; a star marks the hypocenter. Larger aftershocks are marked with a white circle $(4.0 \leq M<5)$ or white triangle $(M \geq 5.0)$ in the appropriate forecast period. best partially explain the spatial differences in $b$-value. We confirmed that the overall spatial pattern of high and low $b$ values is largely independent of the choice of $M_{\mathrm{c}}$ and the analysis period. From Figures 7 and 9 it is apparent that the $b$-value in the first days of the Hector Mine aftershock sequence is significantly lower than the latter period, suggesting that a change in process might take place as the sequences progresses.

Spatial variations in the aftershock decay rate are also evident within the Hector Mine aftershock zone (Fig. 5C). Differences in $p$ between, for example, the northernmost and southernmost segments of the Hector fault are highly significant (Fig. 6). For the Landers fault, spatial variations in $p$ (Fig. 5B) are equivalent to the results by Wiemer and Katsumata (1999).

Hector Mine aftershock activity, measured by the parameter $a^{\prime}$, varies by up to a factor of 5 between the northern and southern ends of the aftershock zone (Fig. 5A), similar to what is observed for the Landers sequence.

The spatial variations of all three parameters can be compared to the mean slip distribution (Fig. 5B). No obvious correlation between slip and seismicity parameters can be derived. For the $b$-value, one can observe that low $b$-values are found only outside the immediate rupture areas and that $b$-values near to the larger slip release tend to be high. We attempted a more detailed correlation between slip and $b$ value in a three-dimensional mapping but failed to establish a statistically significant correlation. These results suggest that either slip distribution has no clear effect on the aftershock seismicity, that other factors (such as fluids, fault strength) need to be taken into account, or that the slip distributions are not precise enough to allow a quantitative correlation. Overall we conclude that the physical mechanism causing the spatial variability remains unclear.

\section{The Variability of Focal Mechanisms}

The results of the mapping of the stress tensor for the Landers and Hector Mine sequences and surrounding regions (Fig. 11) show the predominance of a strike-slip style of faulting with a southwest-northeast trending maximal principal stress. This is consistent with earlier result obtained for the Mojave Desert (Hauksson, 1994; Unruh et al., 1996). Our results also agree with the findings for the Hector Mine sequence by Hauksson et al. (2002), who also analyzed the state of stress in the eastern California shear zone (ECSZ). For this study, we are interested in comparing the stress tensor inversions with other seismicity parameters and other aftershock sequences.

Mapping out the variance of the best fitting stress tensor, we find anomalously high variance near the rupture areas of the two mainshocks (Fig. 11A). The heterogeneity of the stress field is unusually high near the Hector Mine and Landers ruptures, particularly near patches of large slip such as the Emerson-Camp Rock fault in the northernmost part of the Landers sequence. High variances in this volume were previously described by Hauksson (1994). We demonstrate that the high variance is not caused only by the large variability in focal mechanism during the very early part of the aftershock sequence (Fig. 11B,C). We verified our results by applying Gephart's inversion algorithm, and found that its measure of heterogeneity and misfit varies very similarly to Michael's methods. High variance, or high misfit, indicates a poor fit of a homogeneous stress tensor to the observed focal mechanism and indicates high heterogeneity of the stress field (Michael et al., 1990; Gillard and Wyss, 1995; Lu et al., 1997). This heterogeneity can be either temporal or spatial, or both. Because we have not been able to temporally subdivide the samples into more homogeneous subsets (Fig. 11B,C), we assume that spatial heterogeneity of 


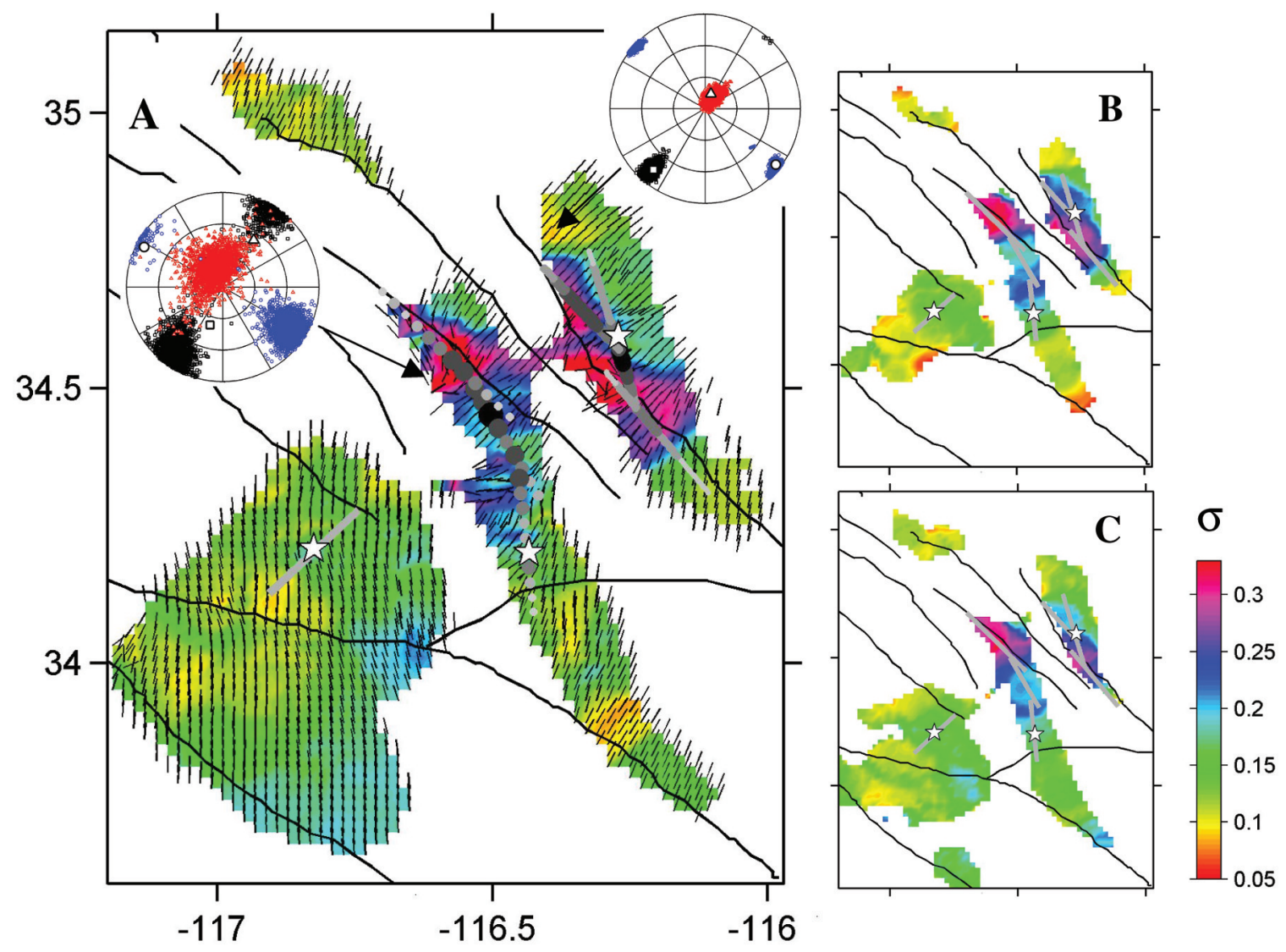

Figure 11. (A) Map of stress inversion results from the first 450 days of aftershock activity. Symbols indicate the orientation of $S_{1}$ obtained from stress tensor inversion of focal mechanisms within $8 \mathrm{~km}$ radius of each node of a grid spaced $2 \times 2 \mathrm{~km}$. Thin black lines mark mapped faults and stars mark the mainshock hypocenters. The mean slip distribution during the events is keyed to symbol size and grayscale (more slip: darker and larger symbol). Color coding indicates the variance of the stress tensor inversion at each node, which is a measure of the heterogeneity of the stress field. High variance $(>0.2)$ marks areas where a homogeneous stress tensor cannot satisfactory explain the observed focal mechanism. For two selected regions, results of the inversion and $95 \%$ uncertainty region are plotted on a stereographic projection (black: $S_{1}$; red: $S_{2}$; blue: $S_{3}$ ). (B) Same as (A), but for the periods 28 June 1992-28 July 1992 (Landers) and 16 Oct. 1999-16 Nov. 1999 (Hector Mine). (C) Same as (A), but for the periods 28 July 1992-30 Sept. 1993 (Landers) and 16 Nov. 1999-31 Dec. 2000 (Hector Mine).

the stress field on scales smaller than our average measurement radii of about $8 \mathrm{~km}$ is the cause. We reduced the mapping radii down to $2 \mathrm{~km}$ and analyzed different depths, but we were not able to significantly reduce the variance. Therefore, we conclude that spatial heterogeneity with scaling length less than $2 \mathrm{~km}$ exists in the stress field near the mainshock ruptures. Mapping stress tensor variance for all of southern California, we confirm that variances greater than 0.3 are unusual for southern California. In addition, we find that variance prior to the mainshocks is generally lower. Therefore, it is highly likely that the heterogeneity in stress is indeed caused by the mainshocks.

A high diversity of focal mechanisms has also been observed after the 1989, $M_{\mathrm{s}} 7.1$ Loma Prieta earthquake (Michael, 1990; Zoback and Beroza, 1993). Two different explanations for this observation have been proposed. (1)
Based on an analysis of the entire aftershock area Zoback and Beroza (1993) observe that the stress field was characterized by uniform, fault-normal compression. They suggest that the diversity of mechanisms is due to systematic variations in strike and dip and they conclude that faults in the region are weak. (2) Based on the inversion of fault-plane solutions for subvolumes of the fault, Michael et al. (1990) and Gephart (1997) argued that the postseimic stress field around the hypocenter was extremely heterogeneous, probably caused by the stress drop during the mainshock. They conclude that one cannot deduce a weak fault from the observed heterogeneity. A similar high heterogeneity of the aftershock focal mechanisms was observed following the Northridge earthquake (Hardebeck et al., 1998).

The results presented in Figure 11 are in good agreement with the heterogeneous postseismic stress field hy- 
pothesis first proposed by Michael et al. (1990). The observation that the highest variance is observed near the largest slip areas can be interpreted as an indication that stress drop during the mainshock is causing the heterogeneity and that stress drop must be a significant fraction of total stress. Based on our $b$-value mapping results (Fig. 5B), we propose the following extension to the heterogeneous postseismic stress field hypothesis: The mainshock causes a redistribution of stress in its immediate vicinity. It is reasonable to assume that the stress will be significantly modified, and overall reduced, near the rupture zone. The complex slip distribution and history during the mainshock causes a very heterogeneous distribution of stress near the fault, and, consequently, this causes variable focal mechanisms and a high variance of the stress-tensor inversions. This high degree of heterogeneity in stress also causes high $b$-values, because numerous small faults in multiple orientations can be activated, resulting in a larger proportion of small as compared to large aftershocks. Some volumes, particularly outside of the immediate rupture area along the extensions of the rupture, are, on the other hand, further loaded with stress. Here the resulting stress field is observed to be more homogeneous (smaller variance) with the mean aftershock magnitude larger (low $b$-value). These are the areas where large aftershocks occur (Fig. 10). We currently cannot offer an explanation why areas opposite the main rupture directivity show an increased hazard and lower $b$-values for both the Landers and the Hector Mine cases. This may either be connected with the rupture dynamics, or pre-existing features of the crust.

\section{Aftershock Hazard Mapping in Near-Real Time}

The PAH maps, shown in Figure 10, are reasonably accurate in forecasting the spatial distribution of ground accelerations. For the Hector Mine sequence, we find that for the first 30 days the forecasted hazard is highest in the area north of the hypocenter, and particularly north of the rupture zone. There is a clear positive correlation of the areas of highest forecasted aftershock hazard, and the subsequent largest aftershocks (Fig. 10). Because the seismicity decays faster to the north of the rupture, as shown by the higher $p$ value in this volume (Fig. 5C), the forecasted HPGA in this region diminishes more quickly than it does near the hypocenter (Fig. 10D). We did not compare the observed acceleration with the forecasted, because we did not account for site amplification, and differences in real and assumed attenuation and source scaling, which would require a more detailed investigation than possible in the framework of this study.

For the Hector Mine aftershock sequence, we implemented the first near real-time computation of the of PAH map. For a 2-month period, maps were automatically updated daily based on the recent seismicity. The first PAH maps for various probability levels, published on the Internet four days after the mainshock, were equivalent to Figure 10A. It showed the higher hazard to the north, which was subsequently followed by three $M 5+$ mainshocks. This promising result substantiates that the correct forecast was not simply obtained by inadvertently optimizing the free parameters in the forecast. Forecasts become more accurate and reliable with time as more events become available; however, as shown in Figure 10, the hazard decreases with time. We consider it encouraging that, given the current level of seismicity monitoring in southern California, meaningful maps can be constructed in a near real-time approach with only 4 days of data. Our group is currently conducting a systematic test of PAH maps and their implementation as a near real-time forecasting tool (Gerstenberger et al., 2001b).

Similar to the Landers sequence (Wiemer, 2000), the hazard posed by the Hector Mine aftershocks is not distributed symmetrically about the mainshock (Fig. 10). For Landers, the hazard south of the hypocenter, and again outside of the actual rupture area, was up to a factor of 3 higher than to the north (Wiemer, 2000, Plate 1). Hector Mine showed the opposite pattern, with higher hazard to the north. Based on these two case studies, we speculate that rupture directivity and slip distribution influence aftershock hazard after large mainshocks, with the highest hazard opposite to the main direction of the ruptures. This hypothesis, of course, needs to be confirmed with additional detailed cases studies. In general, we anticipate that asymmetrical aftershock hazard distributions are common for moderate to large strike-slip mainshocks. The pattern of highest hazard is opposite to the reported triggering of small aftershocks at larger distances (Harris, 1998; Kilb et al., 2000; Gomberg et al., 2001), suggesting that primarily static, and not dynamic transfer of stress through the mainshock is contributing to aftershock hazard; However, the current static stress triggering models (King et al., 1994; Stein et al., 1992; Hardebeck et al., 1998) cannot explain in detail the distribution of aftershock hazard nor the distribution of aftershocks. Nevertheless, although it currently remains uncertain which physical properties within the Earth or which aspects of the mainshock rupture propagation cause the observed spatial variations in aftershocks, we believe that the ability to quantify and forecast the spatial distribution of hazard can nevertheless provide a useful hazard assessment tool.

The computation of PAH maps can occasionally give spurious results. For certain observation or forecast periods, we found that the maximum likelihood estimation of the Omori law is not stable. This happens particularly in the northernmost section of the Hector Mine aftershocks, where the seismicity does not follow the Omori type decay closely, after two $M 5$ class aftershocks occurred (Fig. 6). An improved algorithm that also takes into account larger secondary aftershocks, such as ETAS (Guo and Ogata, 1995, 1997), would likely improve the performance of the forecast. In addition, the definition of source zones necessary to apply SeisRisk III was found to be awkward and difficult to do automatically. Future versions of our code will therefore use a sourceless approach to map hazard (Frankel, 1995).

There are two main advantages of using probabilistic aftershock hazard maps over conventional aftershock hazard assessment: (1) spatial information is available, and there- 
fore areas of higher and lower earthquake probability or hazard along a fault can be distinguished; and (2) the hazard for all magnitude bins is integrated, resulting in comprehensive assessment of hazard rather than a multitude of forecasts for different magnitude bins. Such maps summarize all available information about the aftershock hazard in a comprehensive manner familiar to seismologists and engineers. We envision that after further testing and validation, PAH maps will become a standard format for conveying information from seismologists to emergency response authorities and to the public.

\section{Conclusions}

- Statistically significant spatial and temporal variations in the earthquake size distribution, the aftershock decay rate, and activity exist within the Hector Mine aftershock sequence. The $b$-values are lowest north of the Hector Mine rupture area and are higher along the rupture zone. The $b$ value increases with time during the first 2 months of the sequence.

- Realistic aftershock hazard maps for the Hector Mine sequence were computed as early as 4 days after the mainshock. These maps accurately forecast the distribution of larger aftershocks, which were centered north of the hypocenter.

- Based on a comparison with the Landers aftershock sequence we speculate that for large strike-slip earthquakes, asymmetrical aftershock hazard distributions are common. For both sequences, the highest aftershock hazard was outside the actual mainshock rupture. The pattern of highest hazard, north of Hector Mine and south of Landers, is reversed to the observed triggering of small aftershocks at larger distances, suggesting that static, and not dynamic transfer of stress through the mainshock is governing aftershock hazard. However, current static stress triggering models cannot explain the distribution of aftershock hazard nor the detailed observed distribution of seismicity.

- The heterogeneity of the stress field, deducted from stress tensor inversion of first-motion focal mechanisms, is unusually high near the Hector Mine and Landers fault, particularly near patches of large slip. Stress heterogeneity remains high throughout the sequence. This supports the heterogeneous postseismic stress field hypothesis proposed originally for the Loma Prieta aftershocks.

\section{Acknowledgments}

The author would like to thank M. Wyss, W. Arabasz, V. Langenheim, and an anonymous reviewer for comments and suggestions that greatly helped to improve the manuscript, and to A. Michael for providing stress tensor inversion software and advice. This research was supported by the Southern California Earthquake Center. SCEC is funded by NSF Cooperative Agreement EAR-8920136 and USGS Cooperative Agreements 14-08-0001-A0899 and 1434-HQ-97AG01718. The SCEC contribution number for this paper is 543. This article is Contribution Number 1202 of the Geophysical Institute, ETH Zurich, and Contribution Number 8742 of Caltech, Division of Geology and Planetary Science.

\section{References}

Aki, K. (1965). Maximum likelihood estimate of $b$ in the formula $\log N=$ $a-b M$ and its confidence limits. Bull. Earthquake Res. Inst. 43, 237-239.

Bender, B. (1983). Maximum likelihood estimation of $b$-values for magnitude grouped data. Bull. Seism. Soc. Am. 73, 831-851.

Bender, B., and D. M. Perkins (1987). SEISRISK III: a computer program for seismic hazard estimation. U.S. Geol. Surv. Bull. 1772, 20 pp.

Boore, D. M., W. B. Joyner, and T. E. Fumal (1994). Estimation of response spectra and peak accelerations from Western North American earthquakes: an interim report. U.S. Geol. Surv. Open-File Rep. 93-509.

Frankel, A. (1995). Mapping hazard in the central and eastern United States. Seism. Res. Lett. 66, 8-21.

Frohlich, C., and S. Davis (1993). Teleseismic $b$-values: or, much ado about 1.0. J. Geophys. Res. 98, 631-644.

Gephart, J. W. (1990a). FMSI: a FORTRAN program for inverting fault/ slickenside and earthquake focal mechanism data to obtain the original stress tensor. Comput. Geosci. 16, 953-989.

Gephart, J. W. (1990b). Stress and the direction of slip on fault planes. Tectonics 9, 845-858.

Gephart, J. W. (1997). Spatial variations in stress from the first six weeks of aftershocks of the Loma Prieta earthquake, in The Loma Prieta, California, Earthquake of October 17, 1989: Aftershocks and Postseismic Effects, P.A. Reisenberg (Editor), U.S. Geological Survey, D73-D89.

Gephart, J. W., and D. W. Forsyth (1984). An improved method for determining the regional stress tensor using earthquake focal mechanism data: application to the San Fernando earthquake sequence. J. Geophys. Res. 89, 9305-9320.

Gerstenberger, M. C., S. Wiemer, and D. Giardini (2001a). A systematic test of the hypothesis that $b$ varies with depth in California. Geophys. Res. Lett. 28, 57-60.

Gerstenberger, M. C., S. Wiemer, D. Giardini, E. Hauksson, and L. M. Jones (2001b). Time-dependent hazard assessment for California in near real-time (abstract), Seism. Res. Lett. 72, 273.

Giardini, D. (1999). The Global Seismic Hazard Assessment Program (GSHAP)—1992/1999. Ann. Geofis. 42, 957-974.

Gillard, D., and M. Wyss (1995). Comparison of strain and stress tensor orientation: application to Iran and southern California. J. Geophys. Res. 100, 22,197-22,214.

Gomberg, J., P. Reasenberg, P. Bodin, and R. Harris (2001). Earthquake triggering by seismic waves following the Landers and Hector Mine earthquakes. Nature 411, 462-466.

Guo, Z., and Y. Ogata (1995). Correlation between characteristic parameters of aftershock distribution in time, space and magnitude. Geophys. Res. Lett. 22, 993-996.

Guo, Z., and Y. Ogata (1997). Statistical relations between the paramters of aftershocks in time, space, and magnitude. J. Geophys. Res. 102, 2857-2873.

Gutenberg, R., and C. F. Richter (1944). Frequency of earthquakes in California. Bull. Seism. Soc. Am. 34, 185-188.

Hardebeck, J. L., and E. Hauksson (2001). Stress orientations obtained from earthquake focal mechanisms: what are appropriate uncertainty estimates? Bull. Seism. Soc. Am. 91, 250-262.

Hardebeck, J. L., J. J. Nazareth, and E. Hauksson (1998). The static stress change triggering model: constraints from two southern California aftershock sequences, J. Geophys. Res._Solid Earth 103, 24,42724,437 .

Harris, R. A. (1998). Introduction to special section: stress triggers, stress shadows, and implications for seismic hazard. J. Geophys. Res.Solid Earth 103, 24,347-24,358.

Hauksson, E. (1994). State of stress from focal mechanisms before and after the 1992 Landers earthquake sequence. Bull. Seism. Soc. Am. 84, 917-934.

Hauksson, E. (2000). Crustal structure and seismicity distribution adjacent to the Pacific and North America plate boundary in southern California. J. Geophys. Res. 105, 13,875-13,903. 
Hauksson, E., L. M. Jones, and K. Hutton (2002). The $1999 M_{\mathrm{w}} 7.1$ Hector Mine, California, earthquake sequence: complex conjugate strike-slip faulting. Bull. Seismol. Soc. Am. 92, 1154-1170 (this issue).

Hough, S. E., and L. M. Jones (1997). Aftershocks: are they earthquakes or afterthoughts? EOS 78, 505.

Ishimoto, M., and K. Iida (1939). Observations of earthquakes registered with the microseismograph constructed recently. Bull. Earthquake Res. Inst. 17, 443-478.

Ji, C., D. J. Wald, and D. V. Helmberger (2000). Slip history of 1999 Hector Mine, California earthquake,. Seism. Res. Lett. 71, 224.

Kagan, Y. (1999). Universality of the seismic moment-frequency relation. Pure Appl. Geophys. 155, 537-574.

Kilb, D., J. Gomberg, and P. Bodin (2000). Triggering of earthquake aftershocks by dynamic stresses. Nature 408, 570-574.

King, G. C. P., R. S. Stein, and J. Lin (1994). Static stress changes and the triggering of earthquakes. Bull. Seism. Soc. Am. 84, 935-953.

Kisslinger, C., and L. M. Jones (1991). Properties of aftershocks in southern California. J. Geophys. Res. 96, 11,947-11,958.

Lahaie, F., and J. R. Grasso (1999). Loading rate impact on fracturing pattern: lessons from hydrocarbon recovery, Lacq gas field, France. J. Geophys. Res. 104, 17,941-17,954.

Lu, Z., M. Wyss, and H. Pulpan (1997). Details of stress directions in the Alaska subduction zone from fault plane solutions. J. Geophys. Res. 102, 5385-5402.

Michael, A. J. (1984). Determination of stress from slip data: faults and folds. J. Geophys. Res., 89, 11,517-11,526.

Michael, A. J. (1987). Use of focal mechanisms to determine stress: a control study. J. Geophys. Res. 92, 357-368.

Michael, A. J. (1991). Spatial variations of stress within the 1987 Whittier Narrows, California, aftershock sequence: new techniques and results. J. Geophys. Res. 96, 6303-6319.

Michael, A. J., W. L. Ellsworth, and D. Oppenheimer (1990). Co-seismic stress changes induced by the 1989 Loma Prieta, California earthquake. Geophys. Res. Lett. 17, 1441-1444.

Ogata, Y., M. Imoto, and K. Katsura (1991). 3-D spatial variation of $b$ values of magnitude-frequency distribution beneath the Kanto district, Japan. Geophys. J. Int. 104, 135-146.

Reasenberg, P. A. (1985). Second-order moment of central California seismicity, J. Geophys. Res. 90, 5479-5495.

Reasenberg, P. A. and Jones, L. M. (1989). Earthquake hazard after a mainshock in California. Science 243, 1173-1176.

Reasenberg, P. A., and L. M. Jones (1990). California aftershock hazard forecast. Science 247, 345-346.

Reasenberg, P. A., and L. M. Jones (1994). Earthquake aftershocks: update, Science 265, 1251-1252.

Reasenberg, P. A., and M. V. Matthews (1990). Response to: California aftershock model uncertainties. Science 247, 343-344.

Reasenberg, P. A., and D. Oppenheimer (1985). FPFIT, FPPLOT, and FPPAGE: FORTRAN computer programs for calculating and displaying earthquake fault-plane solutions. U.S. Geol. Surv. Open-File Rept. 85-739.

Scholz, C. H. (1968). The frequency-magnitude relation of microfracturing in rock and its relation to earthquakes. Bull. Seism. Soc. Am. 58, 399-415.

Shi, Y., and B. A. Bolt (1982). The standard error of the magnitudefrequency $b$ value. Bull. Seism. Soc. Am. 72, 1677-1687.

Stein, R. S., G. C. P. King, and J. Lin (1992). Change in failure stress on the southern San Andreas fault system caused by the 1992 magnitude = 7.4 Lander earthquake. Science 258, 1328-1332.

Toda, S., R. S. Stein, P. A. Reasenberg, J. H. Dieterich, and A. Yoshida (1998). Stress transferred by the $1995 M_{\mathrm{x}}=6.9$ Kobe, Japan, shock: effect on aftershocks and future earthquake probabilities. J. Geophys. Res. 103, 24,543-24,565.

Unruh, J., R. Twiss, and E. Hauksson (1996). Seismogenic deformation field in the Mojave block and implications for tectonics of the eastern California shear zone, J. Geophys. Res. 101, 8335-8361.
Urbancic, T. I., C. I. Trifu, J. M. Long, and R. P. Young (1992). Spacetime correlations of $b$-values with stress release. Pageoph 139, 449462.

Utsu, T. (1965). A method for determining the value of $b$ in a formula $\log$ $n=a-b M$ showing the magnitude frequency for earthquakes. Geophys. Bull. Hokkaido Univ. 13, 99-103.

Utsu, T. (1992). On seismicity, Report of the Joint Research Institute for Statistical Mathematics. Institute for Statistical Mathematics, Tokyo, pp. 139-157.

Utsu, T., Y. Ogata, and R. S. Matsu'ura (1995). The centenary of the Omori formula for a decay law of aftershock activity. J. Phys. Earth 43, $1-33$.

Wald, D. J., and T. H. Heaton (1994). Spatial and temporal distribution of slip for the 1992 Landers, California, earthquake. Bull. Seism. Soc. Am., 84, 668-691.

Wiemer, S. (2000). Introducing probabilistic aftershock hazard mapping, Geophys. Res. Lett. 27, 3405-3408.

Wiemer, S. (2001). A software package to analyze seismicity: ZMAP. Seism. Res. Lett. 72, 373-382.

Wiemer, S., and K. Katsumata (1999). Spatial variability of seismicity parameters in aftershock zones. J. Geophys. Res. 104, 13,135-13,151.

Wiemer, S., and S. McNutt (1997). Variations in frequency-magnitude distribution with depth in two volcanic areas: Mount St. Helens, Washington, and Mt. Spurr, Alaska. Geophys. Res. Lett. 24, 189-192.

Wiemer, S., and M. Wyss (1994). Seismic quiescence before the Landers $(M=7.5)$ and Big Bear $(M=6.5) 1992$ earthquakes. Bull. Seism. Soc. Am. 84, 900-916.

Wiemer, S., and M. Wyss (1997). Mapping the frequency-magnitude distribution in asperities: an improved technique to calculate recurrence times? J. Geophys. Res. 102, 15,115-15,128.

Wiemer, S., and M. Wyss (2000). Minimum magnitude of completeness in earthquake catalogs: examples from Alaska, the western US and Japan. Bull. Seism. Soc. Am. 90, 859-869.

Wiemer, S., S. R. McNutt, and M. Wyss (1998). Temporal and threedimensional spatial analysis of the frequency-magnitude distribution near Long Valley caldera, California. Geophys. J. Int. 134, 409-421.

Wyss, M. (1973). Towards a physical understanding of the earthquake frequency distribution. Geophys. J. R. Astron. Soc. 31, 341-359.

Wyss, M., and S. Wiemer (2000). Change in the probabilities for earthquakes in Southern California due to the Landers $M 7.3$ earthquake. Science 290, 1334-1338.

Wyss, M., D. Schorlemmer, and S. Wiemer (2000). Mapping asperities by minima of local recurrence time: the San Jacinto-Elsinore fault zones. J. Geophys. Res. 105, 7829-7844.

Zoback, M. L. (1992). First and second order patterns of stress in the lithosphere: the world stress map project. J. Geophys. Res., 97, 11,70311,728 .

Zoback, M. D., and G. C. Beroza (1993). Evidence for near-frictionless faulting in the 1989 ( $M$ 6.9) Loma Prieta, California, earthquake and its aftershocks. Geology 21, 181-185.

Institut für Geophysik

HPP P 5

ETH Hönggerberg

CH 8093 Zürich

Switzerland

(S.W., M.G.)

Seismological Laboratory

California Institute of Technology

Mail Code 252-21

1200 E. California Blvd.

Pasadena, California 91125

(E.H.)

Manuscript received 23 October 2000. 